\title{
Early results of cardiac transplantation at the Texas Heart Institute
}

\author{
IAN J REECE, OH FRAZIER, ARNAUD PAINVIN, OU JOHN OKEREKE, \\ LINDA B CHANDLER, TW KRUDEWIG, DENTON A COOLEY \\ From the Cardiovascular Surgical Research Laboratories, Texas Heart Institute, Houston, Texas, USA
}

\begin{abstract}
From July 1982 to November 198318 patients (one female) underwent orthotopic cardiac transplantation at the Texas Heart Institute. Prednisone and cyclosporin were used for maintenance immunosuppression in all patients. Cumulative follow up has now been for 90 patient months (0.75-20 months). Rejection occurred in 10 recipients $(56 \%)$ and was fatal in three, giving an incidence of rejection of 0.6 episodes per recipient and a mortality rate of $30 \%$ per episode. At one year $39 \%$ of recipients were free of infection and $73 \%$ free of fatal rejection. Infection episodes occurred on 32 occasions in 14 patients and 24 episodes required treatment. There were no infection related deaths, although the first year actuarial freedom from infection rate was only $24 \%$. With 14 of the 18 patients surviving $(78 \%)$, an actuarial one year survival of $74 \%$, and freedom from major complications in the short term, the efficacy of cyclosporin immunosuppression for cardiac transplantation is confirmed.
\end{abstract}

Cardiac transplantation began at the Texas Heart Institute in $1968^{\prime}$ some six months after Barnard undertook the first operation in man. ${ }^{2}$ Within 18 months 19 patients had undergone transplantation but rejection and infection related deaths caused the programme to be abandoned until more suitable immunosuppressive drugs were available. The continued efforts of the Stanford group showed that long term survival could be achieved with conventional immunosuppressive agents ${ }^{34}$ and over the years this group contributed greatly to our knowledge.

With the availability of the new immunosuppressant drug cyclosporin,? a new programme of cardiac transplantation began at the Texas Heart Institute in 1982. This paper summarises management and early results in our first patients to undergo operation with steroid and cyclosporin immunosuppression.

\section{Patients and methods}

From July 1982 to December 198318 patients underwent orthotopic cardiac transplantation.

Address for reprint requests: Mr IJ Reece, Royal Infirmary, Glasgow G31 2ER.

Accepted 24 April 1984
Details of recipients are summarised in table 1 . Cumulative follow up was 90 patients months (range three to 20 months, mean follow up five months). The operative technique has been described previously. ${ }^{89}$

Cyclosporin (Sandoz) $14 \mathrm{mg} / \mathrm{kg}$ was given orally to each recipient four to six hours before surgery. Two patients who were strong immune responders were treated with cyclosporin for one week and two weeks respectively before operation. Every patient received $0.5 \mathrm{~g}$ of methylprednisone intravenously at the time of cardiectomy and every eight hours for 24 hours after operation. From four hours after operation, cyclosporin $2 \mathrm{mg} / \mathrm{kg}$ was administered by intravenous infusion over 10 hours, twice a day, until the patient was able to take oral fluids, when oral cyclosporin was recommenced at $14 \mathrm{mg} / \mathrm{kg} /$ day. Serial trough serum cyclosporin concentrations were determined and the concentration was maintained at $200-400 \mathrm{ng} / \mathrm{ml}$ by adjustment of the dose.

Prednisone was given on a tapering schedule beginning on the day after transplantation at $120 \mathrm{mg}$ and reaching $30 \mathrm{mg} /$ day by 60 days. After one month at this level the dose was again tapered, to reach $20 \mathrm{mg} /$ day by the 120 th day.

Patients were nursed in a cubicle but no form of barrier nursing was enforced. Infection episodes were managed with antibiotics or other appropriate 
Table 1 Data on the recipients

\begin{tabular}{lllll}
\hline Patient No & Age $(y)$ & Sex & Diagnosis & Functional class* \\
\hline 1 & 39 & $\mathbf{M}$ & Ischaemic heart disease & IV \\
2 & 38 & $\mathrm{~F}$ & Cardiomyopathy & IV \\
3 & 41 & $\mathbf{M}$ & Cardiomyopathy & IV \\
4 & 52 & $\mathbf{M}$ & Rheumatic heart disease & IV \\
5 & 29 & $\mathbf{M}$ & Cardiomyopathy & IV \\
6 & 41 & $\mathbf{M}$ & Ischaemic heart disease & IV \\
7 & 52 & $\mathbf{M}$ & Ischaemic heart disease & IV \\
8 & 39 & $\mathbf{M}$ & Cardiomyopathy & IV \\
9 & 55 & $\mathbf{M}$ & Congenital heart disease & IV \\
10 & 22 & $\mathbf{M}$ & Ischaemic heart disease & IV \\
11 & 40 & $\mathbf{M}$ & Ischaemic heart disease & IV \\
12 & 51 & Ischaemic heart disease & IV \\
13 & 48 & Cardiomyopathy & IV \\
14 & 38 & Ischaemic heart disease (dysrhythmia) & III \\
15 & 49 & Cardiomyopathy & IV \\
16 & 44 & Ischaemic heart disease & IV \\
17 & 42 & Ischaemic heart disease & IV \\
\hline
\end{tabular}

*New York Heart Association criteria.

treatment after cultures had been taken. Frequent multisite cultures were performed for all patients and intravenous and other lines removed as soon as possible after operation.

\section{MANAGEMENT OF REJECTION}

Patients underwent weekly right heart catheterisation and endomyocardial biopsy. Biopsy was performed more frequently if the results were abnormal. Criteria for the diagnosis of rejection followed those of the Stanford group. ${ }^{10}$

In the initial eight cases rejection was managed with a pulse of intravenous methylprednisone $0.5 \mathrm{~g}$ eight hourly for one day and oral prednisone at 200 $\mathrm{mg} /$ day tapering rapidly to $40 \mathrm{mg} /$ day by one month. In the last nine patients, however, rejection was managed by infusion of equine antithymocyte globulin (ATG) seven $\mathrm{mg} / \mathrm{kg}$ over six hours twice a day with $1 \mathrm{~g}$ of methylprednisone a day for three days. ATG was continued for 14 days and gradually withdrawn over the last four days of treatment.

\section{DONOR HEART PROCUREMENT}

Donor hearts for the first eight patients were obtained in Houston, the donor being transferred to an operation room adjacent to the recipient suite. A programme of distant procurement, however, began in August 1983 and since then six hearts have been procured from other cities and four from another hospital in Houston, with transport of the heart to the recipient's operating room. Data on the donors are summarised in table 2.

\section{Results}

Eighteen patients underwent orthotopic cardiac transplantation. There was one female patient, aged
Table 2 Data on the donors

\begin{tabular}{rlll}
\hline Donor No & Sex & Age & Cause of death \\
\hline 1 & M & 27 & Traffic accident \\
2 & F & 29 & G S W, self inflicted \\
3 & M & 20 & Traffic accident \\
4 & M & 14 & Traffic accident \\
5 & M & 18 & Traffic accident \\
6 & M & 18 & Traffic accident \\
7 & M & 19 & G S W, self inflicted \\
8 & M & 36 & G S W, self inflicted \\
9 & M & 17 & Traffic accident \\
10 & M & 33 & Traffic accident \\
11 & M & 22 & Traffic accident \\
12 & M & 24 & Traffic accident \\
13 & M & 39 & G S W, self inflicted \\
14 & M & 20 & Traffic accident \\
15 & M & 18 & Traffic accident \\
16 & M & 19 & Traffic accident \\
17 & M & 17 & G S W, self inflicted \\
18 & M & 18 & G S W, self inflicted \\
\hline
\end{tabular}

G S W-gunshot wound.

38 years; the mean age for the group was 43 years (range 22-55) years. Seven patients $(39 \%)$ had undergone coronary bypass surgery and one had had pulmonary artery banding as a child for a severe atrioventricular canal defect; at later operation it proved impossible to repair the defect. Ischaemic cardiomyopathy was the indication for surgery in eight patients (44\%), idiopathic cardiomyopathy in six $(35.3 \%)$, congenital heart disease in one, and rheumatic heart disease in one. One patient had severe angina associated with ischaemic myopathy and another had uncontrollable ventricular tachycardia and idiopathic cardiomyopathy.

Ischaemic times are recorded in table 3 . The mean ischaemic time was 152 (SD 18) minutes for hearts procured at a distance and 48 (10) minutes for locally procured hearts. 
Table 3 Procurement data on the donor hearts

\begin{tabular}{llcc}
\hline Patient No Local or distant donor & Distance $(\mathrm{km})$ & $\begin{array}{l}\text { Duration of } \\
\text { ischaemia } \\
(\text { min) }\end{array}$ \\
\hline 1 & Local & 0 & 48 \\
2 & Local & 0 & 32 \\
3 & Local & 0 & 35 \\
4 & Local & 0 & 46 \\
5 & Local & 0 & 44 \\
6 & Local & 0 & 39 \\
7 & Local & 0 & 56 \\
8 & Local & 0 & 36 \\
9 & Distant-San Antonio & 304 & 155 \\
10 & Local & 0 & 60 \\
11 & Local & 0 & 56 \\
12 & Local & 0 & 62 \\
13 & Distant-San Antonio & 304 & 164 \\
14 & Local & 0 & 56 \\
15 & Distant-Arlington & 368 & 130 \\
16 & Distant-Fort Worth & 384 & 159 \\
17 & Distant-Austin & 240 & 130 \\
18 & Distant-Amarillo & 800 & 179 \\
\hline
\end{tabular}

One patient died in his sleep on the 22 nd postoperative day. He was having haemodialysis for renal failure, but no definite cause of death was established at necropsy. Rejection was the cause of death in three patients, at 25,32 , and 110 days. The overall hospital mortality rate was therefore $22 \%$ (four patients). Ten patients were diagnosed as having developed and treated for rejection, the incidence being 11 episodes per 100 patient months $(0 \cdot 6$ episodes per patient). Mortality due to rejection was $17 \%$ and mortality per rejection episode $30 \%$. Actuarial analysis showed a $73 \%$ freedom from fatal rejection and $39 \%$ freedom from rejection at 1.5 years with an actuarial survival of $74 \%$. Rejection was diagnosed two to 71 days after operation (mean 22 days) but $90 \%$ of episodes occurred within the first month of implantation.

There were 32 episodes of infection, 24 of which required treatment. Eighteen episodes were bacterial (including two episodes of septicaemia), eight viral, and six fungal. All infections resolved or were successfully treated and there were no infection related deaths. Three patients $(17 \%)$ recovered with no infection episodes, but two of these patients had evidence of rejection and in one of these patients rejection was irreversible. Six other patients treated for rejection developed infection episodes $(75 \%)$, though in one patient an infection episode preceded the diagnosis of rejection; and in the remaining patients, who had no rejection, eight episodes of infection occurred. Thus the incidence of infection episodes was 2.6 per patient in those treated for rejection and 1.6 per patient in those not treated for rejection. The first patient in the series developed rejection on the 12 th postoperative day and after treatment had a series of seven bacterial, two viral, and two fungal infection episodes, which accounted for $34 \%$ of all episodes. There were no disseminated fungal or serious opportunistic infections in the series.

Our first patient also required four operative procedures to eradicate an infected right lower lobe with lung abscess and a cholecystectomy for cholecystitis associated with Escherichia coli septicaemia.

Fourteen patients $(78 \%)$ developed cyclosporin related nephrotoxicity with raised creatinine and urea concentrations, which in one patient required haemodialysis. Twelve patients $(67 \%)$ have required long term treatment for hypertension thought to be a complication of cyclosporin treatment. Grand mal seizures occurred in five patients $(28 \%)$, usually within 48 hours of operation, and were managed with diazepam and phenytoin. Significant depression of cyclosporin concentrations occurred in two patients requiring this treatment. Transient hepatic dysfunction occurred in three patients and a minor rise in serum bilirubin concentration was seen in five other patients.

The average hospital stay was 41 (17-141) days. All survivors who are out of hospital are in functional class I according to New York Heart Association criteria.

\section{Discussion}

Owing largely to the continued effort of Dr Norman Shumway and his colleagues at Stanford University, cardiac transplantation has become a widely accepted treatment for patients with end stage cardiac disease in whom the life expectancy is less than six months and for whom conventional surgery and medication offer no benefit. ${ }^{11}$

In the early series of patients reported from Stanford it became obvious that, although effective immunosuppressive agents were available in the form of steroids and azathioprine, the therapeutic margin of safety was low and infection after rejection treatment was a major cause of death. ${ }^{12}$ Survival from rejection episodes was improved by the use of rabbit antithymoctye globulin ${ }^{13}$ but this agent also induced episodes of infection. These infections were often difficult to treat and were associated with opportunistic organisms such as Aspergillus ${ }^{14}$ is and other organisms not usually found in surgical patients. Techniques of reversed isolation were used but did not appear to have any impact on infection episodes or their outcome. ${ }^{16}$

These factors precluded the widespread adoption of cardiac transplantation while the search for better immunosuppressants continued. The clinical use of cyclosporin has had a major impact on the results of 
all forms of organ transplantation ${ }^{18} 19$ and has encouraged many centres to start clinical heart transplantation again..$^{20}$

Although operative technique plays only a small part in the overall management of these patients, it is important that the donor organ is well protected with cold cardioplegia and cold saline solution $\left(4^{\circ} \mathrm{C}\right)$ during excision and preservation ${ }^{21}$ and that the total ischaemic time is kept to minimum..$^{22}$

Most patients in this series were treated with a low dose infusion of dopamine after surgery to encourage renal perfusion and prevent or attenuate the nephrotoxic effects of cyclosporin. ${ }^{23}$ Patients with a heart rate below 60 beats/minute were managed with an isoprenaline infusion with the addition of ventricular pacing if the systolic blood pressure was higher than $150 \mathrm{~mm} \mathrm{Hg}$. Early postoperative hypertension was very common ( $71 \%$ of cases) and may have played a part in the aetiology of the seizures which occurred. This hypertension was probably related to both cyclosporin therapy and the effects of a new "pump" in a previously hypotensive circulation. This relatively acute hypertension may have produced cerebral oedema akin to hypertensive encephalopathy. Most of the seizures began 48 hours or more after surgery and this delayed onset after an initial "lucid" period would be consistent with the concept of an acute hypertensive encephalopathy. In recent cases attempts have been made to keep the blood pressure below $150 \mathrm{~mm} \mathrm{Hg}$ systolic and this appears to have reduced the occurrence of seizures, but a statistically significant difference has not yet been achieved. Hyperkalaemia, secondary to cyclosporin induced nephrotoxicity, was also common. Low urine output responded well to the infusion of mannitol and frusemide in almost all patients, though the addition of small doses of ethacrynic acid enhanced urine output substantially in the last five cases in which it was used. One patient had persistent oliguria after surgery and required haemodialysis; he died suddenly in his sleep at 22 days, before renal function had returned. The most likely cause for his renal dysfunction was a complication of cyclosporin treatment as there were no other contributing factors of note in the perioperative period.

The incidence of rejection episodes of $0 \cdot 5 /$ patient is substantially lower than that expected with conventional immunosuppression. The mortality rate remains substantial, however, at $30 \%$ per episode and it would appear that a steroid pulse is less effective in reversing rejection in cyclosporin treated patients than in those suppressed with azathioprine and steroids. Griffith et al $^{17}$ noted much improved survival with a lower rejection related mortality rate when antithymocyte globulin was added to the anti- rejection treatment. We adopted this treatment in our last four rejection episodes, three of which were controlled.

By reducing the number and severity of rejection episodes the incidence of infection is also greatly reduced. In this series there were no infection related deaths, whereas previous reports implicated infection in about $25 \%$ of deaths. The close relationship between antirejection treatment and infection episodes first reported by Remington $e t a^{24}$ and confirmed by Mason et al ${ }^{12}$ is manifest in our series, though infection still occurred in patients not undergoing treatment for rejection. The low incidence of opportunistic fungal infections (one case of aspergillus infection in the left upper lobe) contrasts with previous reports and is particularly important as these infections have contributed substantially to the hospital mortality in the past. ${ }^{15}$ Although the follow up interval in this series is relatively short, results that are similar to those of other series ${ }^{5}$ are encouraging. Caution must be applied in extrapolating these short term results as graft atherosclerosis and fibrosis, especially in rejection treated grafts, may still prove to be a problem. Interstitial fibrosis has been noted in endocardial biopsy specimens from patients treated with cyclosporin and has been attributed to the drug. ${ }^{10}$ In hearts procured from a distance late fibrosis may also be a consequence of prolonged ischaemia and may impair long term cardiac function.

Perhaps the major reason for continued caution in the use of cardiac transplantation is the as yet unproved long term effects of cyclosporin, both in the graft and in the recipient. Cyclosporin is known to produce side effects such as nephrotoxicity, hepatotoxicity, flushing, tremor, limb pain, and hirsutism. These are usually dose related. Moreover, cases of lymphoma have been reported in patients taking the drug ${ }^{25}$ and little is known about its long term effects. Until these doubts are resolved, or other less toxic agents become available, cardiac transplantation should still be reserved for those with terminal cardiac disease, though in this group of patients it now offers excellent palliation.

\section{References}

' Cooley DA, Bloodwell RD, Hallman GL. Cardiac transplantation for advanced acquired heart disease. $J$ Cardiovasc Surg (Torino) 1968;9:403-5.

${ }^{2}$ Barnard CN. The operation. A human cardiac transplant: an interim report of a successful operation at the Groote Schuur Hospital, Cape Town. S Afr Med 1967;41:1271-4.

${ }^{3}$ Gaudiani VA, Stinson EB, Alderman E, et al. Long term survival and function after cardiac transplantation. Ann Surg 1981;194:381-5. 
${ }^{4}$ Pennock JL, Oyer PE, Reitz BA, et al. Cardiac transplantation in perspective for the future. Survival, complications, rehabilitation and cost. J Thorac Cardiovasc Surg 1982;83:168-77.

5 Jamieson SW, Oyer PE, Reitz BA, et al. Cardiac transplantation at Stanford. Heart Transplantation 1981;1:86-91.

' Shumway NE. Recent advances in cardiac transplantation. Transplant Proc 1983;15:1221-4.

${ }^{7}$ Borel JF. Immunosuppressive properties of cyclosporin A (CyA). Transplant Proc 1980;12:233.

${ }^{8}$ Cooley DA. Techniques in cardiac surgery. Philadelphia: WB Saunders, 1984.

${ }^{9}$ Hallman GL, Cooley DA. Operative technique for cardiac transplantation. Laval Medical 1970;41:191-4.

${ }^{10}$ Billingham ME. Diagnosis of cardiac rejection by endomyocardial biopsy. Heart Transplantation 1981;1:25-30.

"Copeland JG, Salomon NW. Recipient selection for cardiac transplantation. Ariz Med 1980;37:758-60.

${ }^{12}$ Mason JW, Stinson EB, Hunt SA, Schroeder JS, Rider AK. Infections after cardiac transplantation: relation to rejection therapy. Ann Intern Med 1976;85:69-72.

${ }^{13}$ Oyer PE, Stinson EB, Bieber CP, Reitz BA, et al. Diagnosis and treatment of acute cardiac allograft rejection. Transplant Proc 1979;9:296-303.

${ }^{14}$ Gurwith MJ, Stinson EB, Remington JS. Aspergillus infection complicating cardiac transplantation: a report of five cases. Arch Intern Med 1971;128:541-5.

is Stinson EB, Bieber CP, Griepp RB, Clark DA, Shumway NE, Remington JHS. Infection complications after cardiac surgery in man. Ann Intern Med 1971;74:22-36.

${ }^{16}$ Williams TW Jr. Prevention of infections in transplanta- tion patients. Transplant Proc 1972;4:707-10.

${ }^{17}$ Griffith BP, Hardesty RL, Thompson ME, Dummer JS, Bahnson HT. Cardiac transplantation with cyclosporin: The Pittsburg experience. Heart Transplantation $1983 ; 2: 251-6$.

${ }^{18}$ Starzl TE, Klintmalm GBG, Porter KA, Iwatsuki S, Schroter GPJ. Liver transplantation with the use of cyclosporin A and prednisone. $N$ Engl J Med 1981;305:266-70.

${ }^{19}$ Calne RY, White DJ, Thirus S, Evans DB. CyA in clinical organ grafting. Transplant Proc 1981;13:349-50.

${ }^{20}$ Cooley DA, Frazier OH, Kahan BD. Cardiac transplantation with the use of cyclosporin A for immunologic suppression. Texas Heart Institute Journal 1982;3:247-52.

${ }^{21}$ Hardesty RL, Griffith BP, Deeb GM, Bahnson HT, Starzl TE. Improved cardiac function using cardioplegia during procurement and transplantation. Transplant Proc 1983;15:1253-5.

${ }^{22}$ Billingham ME, Baumgartner WA, Watson DC, et al. Distant heart procurement for human transplantation: ultrastructural studies. Circulation 1980;62, suppl 1: 11-9.

${ }^{23}$ Sibley RK, Rynasiewicz J, Ferguson RM, et al. Morphology of cyclosporin nephrotoxicity and acute rejection in patients immunosuppressed with cyclosporine and prednisone. Surgery 1983;94:225-33.

${ }^{24}$ Remington JS, Gaines JD, Griepp RB, Shumway NE. Further experiences with infection after cardiac transplantation. Transplant Proc 1972;4:699-705.

${ }^{25}$ Calne RY, Rolles K, White DJG, et al. Cyclosporine A initially as the only immunosuppressant in 34 recipients of cadaveric organs: 32 kidneys, 2 pancreases and 2 livers. Lancet 1979; ii:1033-9. 